\title{
Resenha do filme Mulan (2013): problemáticas de gênero
}

\author{
Rafael Marques Garcia' \\ Erik Giuseppe Barbosa Pereira ${ }^{2}$
}

\section{RESUMO}

Trata-se da resenha do filme "Mulan" (2013) dirigido por Tony Bancroft e Barry Cook e produzido pela Disney-MGM Studios, que conta a aventura de uma jovem que, disfarçada de guerreiro, se une a um exército exclusivamente masculino, e decide colocar em risco sua vida para salvar seu pai e sua Pátria. Durante a trama, é possível perceber a teoria da performatividade de gênero, enfatizado pelo caráter fluido das construções de identidades e corporalidades de gênero transitados pelas/os personagens. Embora lançado em 1998, foi relançado em Blu-ray no Brasil em 2013, reacendendo discussões pertinentes aos Estudos Culturais e de Gênero e que estão diretamente ligados ao universo de influência, principalmente infantil.

Palavras-chave: Corpo. Gênero. Sexualidade. Cinema. Performance

1 Licenciado em Educação Física. Mestrando em Educação Física na Universidade Federal do Rio de Janeiro (UFRJ). Rio de Janeiro/Rio de Janeiro, Brasil. E-mail: rafa.mgarcia@hotmail.com

2 Doutor em Ciências do Exercício e do Esporte. Professor efetivo da Universidade Federal do Rio de Janeiro (UFRJ). Rio de Janeiro/Rio de Janeiro, Brasil. E-mail: egiuseppe@eefd.ufrj.br 
julho/2018

\section{Review of the film Mulan (2013): problematics of gender}

\section{ABSTRACT}

This is the story of the film "Mulan" (2013) directed by Tony Bancroft and Barry Cook and produced by Disney-MGM Studios, the animation tells the adventure of a young woman who, disguised as a warrior, joins an exclusively male army, and decides to put your life in risk to save her father and country. During the plot, it is possible to perceive the theory of gender performativity, emphasized by the fluid character of the constructions of identities and corporalities transited by the characters. Although dated in 1998, it was reissued in Blu-ray in Brazil in 2013, reigniting relevant current issues to culture and gender studies, being directly linked to the influence of child universe

Keywords: Body. Gender. Sexuality. Movie. Performance

\section{Revisión de la película Mulan (2013): problemas de género}

\section{RESUMEN}

Se trata de la revisión de la película "Mulan" (2013) dirigida por Tony Bancroft y Barry Cook y producida por Disney-MGM Studios. La animación narra la aventura de una joven disfrazada de guerrero que se une a un ejército exclusivamente masculino, donde se ve amenazada para salvar a su padre y su país. Durante la trama, se puede ver la teoría de la performatividad de género enfatizada por la naturaleza fluida de la construcción de las identidades de género y de la corporalidad realizado por los personajes. Aunque data de 1998, fue relanzado en Blu-ray en 2013 en Brasil, reactivando discusiones relevantes para los estudios culturales y de género y que están directamente vinculados con el universo de la influencia de los niños.

Palabras clave: Cuerpo. Género. Sexualidad. Cine. Performance 


\title{
INTRODUÇÃO
}

Inspirada na heroína popular chinesa Hua Mulan, a obra é ambientada na vasta e poética paisagem do país. Esta aventura conta a história de uma jovem destemida e corajosa que, disfarçada de guerreiro, se une a um exército exclusivamente masculino e decide colocar em risco a sua vida para salvar seu pai e sua Pátria.

Dirigido pelos especialistas e experientes em obras de animações, os americanos Tony Bancroft e Barry Cook, Mulan foi lançado durante o renascimento da produtora Disney-MGM Studios, sendo o primeiro de três animações produzidos em Orlando, obtendo indicações ao Globo de Ouro e ao Prêmio da Academia, e ganhando vários prêmios Annie.

Por seu caráter de animação, a obra destina-se ao público infantil, mas ganha notoriedade quando desbrava a desnaturalização da sexualidade humana e a desconstrução do próprio conceito de gênero em suas performances e características corporais.

Tomemos de início a concepção de gênero como uma das primeiras construções das diferenças sexuais que atua de forma hierarquizante e (re)produtora das relações de poder entre homens e mulheres (LOURO, 2010), onde podemos estabelecer uma relação com a representação dos corpos nas diversas esferas sociais.

\begin{abstract}
De acordo com as mais diversas imposições culturais, nós os construímos de modo a adequá-los aos critérios estéticos, higiênicos, morais, dos grupos a que pertencemos. As imposições de saúde, vigor, vitalidade, juventude, beleza, força são distintamente significadas, nas mais variadas culturas e são também, nas distintas culturas, diferentemente atribuídas aos corpos de homens ou de mulheres. Através de muitos processos, de cuidados físicos, exercícios, roupas, aromas, adornos, inscrevemos nos corpos marcas de identidades e, consequentemente, de diferenciação. Treinamos nossos sentidos para perceber e decodificar essas marcas e aprendemos a classificar os sujeitos pelas formas como eles se apresentam corporalmente, pelos comportamentos e gestos que empregam e pelas várias formas com que se expressam. (LOURO, 2010, p. 9-10).
\end{abstract}

Cientes de que as normas de gênero são estruturadas e perpetuadas por diversas instâncias sociais, dentre elas a família, religião, escola, política, entre outros, o cinema surge como uma principal ferramenta para disseminação de variados conteúdos ao público para qual se destina (XAVIER FILHA, 2016). Torna-se importante problematizar, neste contexto, como a produção cinematográfica tece seus roteiros objetivando atingir determinado público através de diálogos, signos, significações e marcadores identitários (idem), uma vez que determinado filme pode ser assistido e reassistido inúmeras vezes, favorecendo a internalização de discursos, gestos e linguagens, ensinando hábitos, costumes, atitudes e comportamentos (SABAT, 2001).

Inspirados pelas autoras, podemos compreender o cinema como integrante de um artefato social maior, o protótipo de uma matriz heterocompulsória, binária e sexista que, quando veiculado ao público infantil, ganha notoriedade enquanto instrumento disseminador de aprendizagem social e de constituição da infância. 
Um olhar crítico sobre a extensa filmoteca infantil aponta um dado interessante a se pensar: já não são apenas artifícios de diversão, mas sim educadores culturais que, de certa forma, constituem identidades sociais e sexuais normatizadas, bem como suas desigualdades hierárquicas, definitivas e imutáveis entre homens e mulheres (SABAT, 2001).

$\mathrm{O}$ cinema encontra-se intimamente ligado às reconfigurações de valores sociais, preconceitos e lutas, onde a indústria cinematográfica inclina-se às modificações da contemporaneidade para ecoar tais fenômenos (IGLESIAS, ZAMORA, 2013). Atua, desta forma, como fomentador da cultura visual, isto é, através de uma interação dialógica com seu público espectador, desencadeia inúmeras reações, tais como prazer, felicidade, encantamento, ódio, raiva, angústia, horror, entre outros. Através da materialização de signos e simbologias, esse processo se estende para além das telas, incutindo e/ou reformulando no sujeito expectador valores e moralidades que são reproduzidos nas ações cotidianas da vida real.

Atrelado à cultura visual avulta-se uma nova competência, que é a linguagem. Seu papel é nomear e constituir episódios, situações, sentimentos e vivências através de representações simbólicas a partir de um contexto material, ou seja, o ato da nomeação torna-se possível apenas quando existe um sentido atrelado a ela de forma materializada, seja um texto, cena, fotografia ou palavra (SILVA, 1999). O casamento destes indiciadores redunda-se em uma complementação construtiva que possibilita, por fim, anunciações, anseios e reconhecimentos.

Um exemplo clássico desta premissa é o tão conhecido final "felizes para sempre". Essa sentença, recorrente principalmente em filmes infantis, encontra-se referta de significados em torno de uma contemplação plena de vida que só pode ser alcançada através da união romântica entre homem e mulher, suprimindo as demais alternativas, além de veicular subliminarmente ideais de fracasso e insucesso aos heterodissidentes. Tais sentidos sinalizam em meninos e meninas o que fazer, vestir e dizer para alcançar a tão desejada sentença: aos primeiros, competem-Ihe demonstrar iniciativa, força, virilidade, coragem, valentia e esperteza, restando às segundas a fragilidade, docilidade, sensualidade, ingenuidade, pureza e graciosidade, convergindo, assim, para a adoção/ocupação de posturas, posições, espaços físicos e sociais dessemelhantes, em uma lógica binária, contraposta, complementar e relacional (BALISCEI, CALSA, STEIN, 2016).

É interessante, ainda, refletir sobre como a produtora do filme, a Disney, vem historicamente legitimando certos ensinamentos e pedagogias culturais. Existe uma diferença acentuada entre a representação/retratação de heróis/heroínas e vilãos/vilãs: geralmente dos(as) primeiros(as) emanam características heteronormativas sobre corpo e beleza, enquanto que dos(as) segundos(as) evidenciam-se aspectos caricaturados exagerados, associando-os aos atributos de homossexualidade (SANTOS, 2015). Desta forma, sujeitos do primeiro grupo são concatenados exclusivamente a heterossexuais e fadados ao sucesso e/ou "felizes para sempre", enquanto que os sujeitos do segundo grupamento estão relacionados às sexualidades desviantes e malfeitores, devendo ser encarados com estranhamento no filme e, também, nos demais contextos sociais, contribuindo assim para uma sustentação preliminar de preconceitos com base nos preceitos de normalidades que são daí propagados (BALISCEI, CALSA, STEIN, 2016). 
O filme Mulan, da produtora em questão, por se tratar de uma obra destinada ao público infantil, torna-se interessante por atrair o foco de sua narrativa aos pequenos utilizando-se de conteúdos complexos acerca dos gêneros e sexualidades, o que possibilita a discussão sobre a temática desde cedo. A seguir, faremos uma resenha do filme elencando as principais mensagens que são veiculadas através das imagens, dos discursos e das interpretações das/os personagens.

Para os procedimentos de análise, organizamos a resenha em 5 etapas. Na etapa 1, reunimo-nos em um espaço reservado para assistir ao filme sem interrupções. Na etapa 2, neste mesmo local em outra data, reassistimos ao filme congelando-o nas cenas emblemáticas, transcrevendo falas, músicas, ações, gestos e atitudes dos(as) personagens. Na etapa seguinte, analisamos todo o material transcrito conforme nosso referencial teórico e o objetivo do estudo, organizando-o em unidades analíticas; na quarta etapa, tecemos nossos comentários e organizamos o trabalho final e; na última, reassistimos ao filme para rever mensagens, símbolos e ícones que poderiam ter passado despercebidos.

\section{LUZ, CÂMERA, AÇÃO!}

Nessa produção, as questões de gênero estão presentes do começo ao fim, ao começar pela primeira frase do Imperador: "Um homem pode ser a diferença entre a vitória e a derrota". Subentende-se que o soldado é representado apenas pelo homem e apenas este pode ser capaz de defender sua pátria (o que soa cômico no fim, pois é justamente uma mulher que se sobressai ante a esta sociedade).

Com o andamento do filme, percebemos que o papel de Mulan é reproduzir as qualidades atribuídas ao gênero feminino. Deve ser "Calma e reservada, graciosa, educada, delicada, refinada, equilibrada, pontual!3". Essa concepção parte de si própria e também de seus familiares. Em uma das sessões inicias do filme, Mulan deve visitar uma casamenteira para provar as competências que lhe tornam mulher. Nesta tomada, temos como pano de fundo a música "A Casamenteira":

Este caso é muito raro / Mas jeito sempre tem / Um banho perfumado / E vai ficar bem / E então vai estar / Pronta para encontrar seu par / Uma noiva mais que exemplar / Traz mais honra a todas nós / Vai ver só / Virá um / Bom rapaz que não tem vício algum / Tendo sorte / Não é incomum / Traz mais honra a todas nós / A moça vai trazer a grande honra ao seu lar / Achando um bom par / Com ele se casar / Mas terá que ser bem calma / Obediente / E ter dispor / Com bons modos e com muito amor / Traz mais honra a todas nós / Servimos ao imperador que é o nosso protetor / Com muita devoção / E sempre com ardor / Mas não vá fracassar / Com a sorte um dia vai achar / Queira sempre a junto a ele estar / Traga honra a todas nós / Pérolas, são belas / Então vamos mostrar / E leve um grilo, traz sorte / Que até você vai brilhar / Ancestrais, ouçam bem / Eu vos peço proteção também / Pra que encontre logo um alguém / E ao meu pai eu vou honrar / Assustadas em fileira / Vamos à

3 Falas da própria personagem enquanto estuda para ser aprovada pela Casamenteira. 
casamenteira / Ancestrais, cuidem bem / Destas pérolas que aqui tem / Prontas para aprender também / Como honrar a todos nós / Como honrar a todas / Como honrar a todas / Como honrar a todas / Como honrar a todas / Como honrar a todas nós.

Mulan chega atrasada, montada à cavalo e com uma palha em seus cabelos esvoaçados. Sua mãe não esconde a decepção em ver a filha se comportando daquela maneira, sendo apoiada pelas demais da família, que atribuem àquilo um aspecto de raridade, mas ainda reversível após um banho perfumado. Somente após seu embelezamento, estará pronta para encontrar seu par, um bom rapaz e sem vícios, tornando-se assim uma noiva exemplar, calma, obediente, prestativa e com bons modos, por fim, digna de honra. Fica claro o papel social que a mulher deve desempenhar: casar com um bom rapaz e comportar-se como uma esposa bela, feminina e maternal (GOELLNER, 2003) para só então trazer honra à sua família. Para além dessas funções, a letra da canção nos remete ao apelo de um corpo ideal de mãe e ao seu papel na hierarquia de gênero, submissa e servente ao marido (HEILBORN, 1993).

Ao ser avaliada pela casamenteira, a protagonista se desconcentra com o grilo da sorte e tudo torna-se um desastre. Na fala final da avaliadora, "Você é uma desgraça! Pode parecer uma noiva, mas você nunca trará à sua família honra!", percebe-se que a garota, embora dotada dos atributos graciosos de uma mulher (GOELLNER, 2003) jamais traria honra à família porque não cumpria os requisitos de uma boa esposa. Novamente, reforça-se a ideia de que apenas casando com um rapaz e tornando-se mãe é que Mulan seria digna de mérito.

Ao retornar e em crise, Mulan acredita não corresponder aos padrões que lhe são cobrados. Nesta sessão, temos como pano de fundo a música "Reflexão":

\begin{abstract}
Olhe bem / A perfeita esposa / Jamais vou ser / Ou perfeita filha / Eu talvez / Tenha que me transformar / Vejo que / Sendo só eu mesma / Não vou poder / Ver a paz reinar / No meu lar / Quem é que está aqui / Junto a mim / Em meu ser / É a minha imagem / Eu não sei dizer / Como vou desvendar / Quem sou eu / Vou tentar / Quando a imagem / De quem sou / Vai se revelar / Quando a imagem / De quem sou / Vai se revelar.
\end{abstract}

A protagonista revela não se identificar com sua imagem em função da não-adequação com os modelos esperados para uma mulher/esposa, dizendo que talvez tenha que se transformar para enfim trazer a paz ao seu lar e à sua família. Neste processo, podemos perceber que uma imposição binária dos gêneros parece não contemplar todos os corpos. Mulan não tem saída nesse sistema, uma vez que não consegue incorporar em si os atributos sociais e familiares que Ihe recaem em função de sua genitália.

Seu pai a consola, atribuindo à mesma uma comparação com uma flor - a delicadeza e formosura, aspectos pertencentes ao universo feminino e que, portanto, só poderiam ser atribuídos a uma mulher. A naturalização desses atributos, bem como da sensibilidade, fragilidade e docilidade associados à mulher são resultados de um processo histórico de construção da feminilidade (GOELLNER, 2007). 
O momento de consolação é interrompido quando representantes do Império Chinês chegam ao vilarejo para distribuir convocações para defender a China da invasão dos hunos. Ciente da motricidade deficiente de seu pai, Mulan interrompe seu processo de intimação e é coagida pelo conselheiro imperial: "Seria bom ensinar a sua filha a conter a língua na presença de Ordem". O pai escandalizado murmura: "Mulan, isso é uma desonra!". Analisando o ocorrido à luz das relações de poder (HEILBORN, 1993), podemos identificar duas maneiras em que elas se manifestam: a primeira, diz respeito aos gêneros, uma vez que apenas homens estão qualificados e disponíveis para ocupar as posições de representantes do Império, exercendo discursos coercitivos que subalternam os guerreiros reservistas e mais ainda as mulheres, estas devendo se calar na presença de homens de poder, serem submissas; o segundo diz respeito ao cargo ocupado pelos representantes que, numa organização hierárquica, está acima dos demais membros das comunidades locais, estabelecendo uma relação de "manda quem pode, obedece quem tem juízo".

A partir do comentário do pai de Mulan, percebemos ainda que, para além de corroborar com a visão hierárquica supracitada, existe uma política repressiva das manifestações que subvertem o senso comum. Diante do público e adotando seu papel de guerreiro reservista, o pai não titubeia em repreender a atitude da filha, uma vez que ela deveria saber seu lugar naquela composição. Para Negreiros e Feres-Carneiro (2004), na organização familiar, verifica-se a dimensão pública-masculina é mais valorizada que a privada-feminina, e a participação do homem ou da mulher na área pertencente ao outro é eventual e descontínua, o que justificaria a atitude do pai.

Na cena seguinte, quando o pai transparece virilidade e potência em seu treinamento pessoal, Mulan assiste a cena e novamente não se conforma com a necessidade de seu genitor querer demonstrar a todo custo sua utilidade mesmo com uma lesão comprometedora. Preocupada com a integridade física do mesmo, Mulan passa a noite em claro arquitetando um plano para poder salvá-lo. Assume, então, outra identidade: corta e amarra os cabelos, veste a armadura, bainha a espada e segue para a concentração do Exército para representar sua família na defesa da China.

Decorrente de sua ação, os ancestrais da família despertam para uma sessão. Uma mulher fantasma já sai reclamando que a garota é encrenqueira, e seu marido já replica dizendo que ela puxou isso do seu lado da família. Percebemos também que a ideia de Mulan é condenada pelo fato de sua conduta ser interpretada como "transformista". Mushu, o dragão, diz estar encrencado porque a garota "resolveu dar uma de soldado machão", atribuindo ao guerreiro apenas um sexo, o masculino, ou seja, anulando a possibilidade de que mulheres também poderiam fazer parte do Exército chinês por não serem "machões", em uma clara demarcação de territórios para homens e mulheres (GOELLNER, 2007).

Mulan agora parteja outra personalidade, nomeada de Ping. Neste processo, ela adota os estereótipos qualificadores do masculino: engrossa a voz, torna-se agressiva, muda seu jeito de andar e comportar-se em público, passando a bater nos colegas para cumprimentá-los e a cuspir no chão. Esse ritual dissemina os princípios de uma corporação de elementos próprios do homem, do guerreiro, "Pelo uso de gestos agressivos ao se cumprimentarem, por atos de demonstração de força, ameaças de agressão e brincadeiras 
de lutas, meninos-alunos são convocados a ocuparem a posição de guerreiros" (REIS; PARAÍSO, 2013, p. 1248).

Em outras palavras, Mulan performa-se num corpo masculino, à luz da teoria da performatividade de Butler (2015). Para a autora, a identidade do sujeito faz-se construída socialmente sobre os corpos através de uma lógica heteronormativa compulsória, sendo orquestrada pela constante repetição de gestos e atos, tornando-se performativo por reproduzir sujeitos masculinos e femininos através da incorporação de discursos reguladores e que incidem sobre os corpos e suas corporalidades. Assim, Mulan precisa treinar e repetir os gestuais de um homem guerreiro para incorporar e transparecer tal identidade masculina. Essa performance ${ }^{4}$ de gênero encontra-se cerceada por uma estrutura rígida - dita heterocompulsória - que limita suas possibilidades através dos atributos supracitados.

Pensando em um contexto histórico-social, uma performance se materializa através de práticas sociais e corporais legitimadas através do exercício reiterativo (SCHECHNER, 2011), sendo uma das manifestações que desdobram-se a partir da performatividade (BUTLER, 1993). Neste caso,

Performances marcam identidades, dobram o tempo, remodulam e adornam o corpo, e contam estórias. Performances - de arte, rituais, ou da vida cotidiana são "comportamentos restaurados", "comportamentos duas vezes experenciados", ações realizadas para as quais as pessoas treinam e ensaiam (SCHECHNER, p. 29).

A performance é, portanto, uma atividade habitual, concernida por automatismos que agregam significados a condutas reproduzidas conforme tradições, memórias, valores e moralidades sociais. Segundo o autor, este processo se exemplifica através das seguintes etapas: observação, prática, imitação, correção e repetição. A interação destas fases imbrica no desempenho performático, isto é, na reprodução de determinadas qualificações de símbolos e seus significados que envolvem improviso, pró-atividade, ludicidade e atuação do performer em questão (SCHECHNER, 2011).

Ping, sob esta conjuntura, pode ser indicado enquanto resultante da performance de Mulan: através da introjeção e externalização de qualificações masculinas, do ser, fazer e agir como homem, (re)constroi-se a identidade do guerreiro masculinizado, que deve cuspir, bater, ser agressivo, descuidado com a higiene e imprudente. Ping se atualiza a todo instante sob estes moldes, sempre auxiliado pelo seu guardião Mushu, que atua nesta esfera como policiador da sexualidade. Na verdade, todas as reações dos convocados e integrantes do Exército chinês são performances, pois todos os homens ali presentes precisam incorporar e (re)afirmar a identidade aguerrida do macho alfa, apropriando-se, portanto, dos aspectos ditos clássicos do ser masculino. Ainda, vale lembrar que cada performance é em si um ato não permanente e não enrijecido, possibilitando inúmeras recombinações, alterações, permanências e reconhecimentos que são valorados, sobretudo readaptados,

4 Uma performance se configura a partir de um desdobramento das manifestações de performatividade. Esta, por sua vez, possibilita a performance, ao mesmo tempo que a potencializa e a limita (BUTLER, 1993). 
socioculturalmente (SCHECHNER, 2011), o que justificaria as inúmeras manifestações de masculinidades experenciadas pelos atores do filme em questão.

Entendendo a performance enquanto dispositivo reiterador de identidades, tal premissa embasa os pensamentos de Mushu quando Mulan reclama da "nojeira" promovida pelos soldados. Nessa cena, o dragão afirma: "[...] são homens e você vai ter que ser igual a ele, então presta atenção!". Tal assertiva naturaliza o descuido da higiene no universo masculino, além de sugerir que Mulan, enquanto Ping, siga o mesmo caminho de performance através das etapas defendidas por Schechner (2011). A briga que se inicia na tomada seguinte nos revela a afirmação das masculinidades por parte dos soldados homens. Resolve-se o problema na base da violência, onde segundo Reis e Paraíso (2013) as masculinidades incidem diretamente na criação de alunos-guerreiros: "Atacar mais, ser um campeão na luta, atingir o impossível, desmaiar o colega é ponto para quem está guerreando, para quem é convocado a ser mais guerreiro" (idem, p. 1256), o que torna o indivíduo macho e, dentro desta categoria, estabelece um ranking entre os mais e menos machos de modo a mais uma vez consolidar uma hierarquia (HEILBORN, 1993).

Ao longo do treinamento dos soldados, temos como fundo musical a canção Não Vou Desistir de Nenhum:

Vamos à batalha / Guerrear, vencer / Derrotar os hunos / É o que vai valer / Vocês
não são o que eu pedi / São frouxos e sem jeito algum / Vou mudar, melhorar / Um
por um / Calmo como a brisa / Chamas no olhar / Uma vez centrado / Você vai
ganhar / São soldados sem qualquer valor / Tolos e sem jeito algum / Mas não vou
desistir de nenhum / Alguns quilos vou perder / Diga a todos que eu já vou / Não
devia ter deixado de treinar / Não deixa ele te bater / Espero que não saibam quem
sou / Eu queria mesmo é saber nadar! / Homem ser! / Seremos rápidos como um rio
/ Homem ser! / Com força igual a de um tufão / Homem ser! / Na alma sempre uma
chama acesa / Que a luz do luar nos traga inspiração / O inimigo avança / Quer nos
derrotar / Disciplina e ordem / Vão nos ajudar / Mas se não estão em condições de
se armar e combater / Como vão guerrear e vencer? / Homem ser! / Seremos rápidos
como um rio / Homem ser! / Com força igual a de um tufão / Homem ser! / Na
alma sempre uma chama acesa / Que a luz do luar nos traga inspiração! / Homem
ser! / Seremos rápidos como um rio / Homem ser! / Com força igual a de um tufão
/ Homem ser! / Na alma sempre uma chama acesa / Que a luz do luar nos traga
inspiração!

Através da canção, podemos acusar a existência de toda uma cobrança aos soldados para que evoluam agressivamente e nas técnicas de combate, pois isso é o que se espera de guerreiros machos (REIS; PARAÍSO, 2013). Para além disso, podemos inferir também que "homem ser" é reproduzir aspectos de força, coragem e virilidade (GOELLNER, 2007), que estão associados aos aspectos naturais "tufão" e "rio", ou seja, são características desempenhadas apenas pelo sexo masculino devido ao seu teor robusto.

Na próxima cena, Mulan banha-se no rio sob a justificativa de que não quer cheirar a homem - reafirmando a ideia universal de descuido higiênico masculino - e se esconde dos demais companheiros quando estes aparecem, no entanto é descoberta e rapidamente 
performa Ping. O soldado Yao ridiculariza-os porque não o derrubam da pedra, e usa, para tanto, o adjetivo "garotinhas". Ling faz o mesmo ao dizer para Ping "deixa de ser mulherzinha!" e ir confrontar Yao. Percebemos que atribuir um termo feminino ao masculino é motivo de sátira e inferioridade, conforme o discurso das hierarquias de gênero (HEILBORN. 1993). O mesmo foi relatado na pesquisa de Paraíso (2011) sobre raciocínios generificados no espaço escolar, onde meninos eram punidos e realocados na fila das meninas, o que

[...] reforça dicotomias existentes na sociedade para normalizar e regular os corpos, produzindo sujeitos masculinos e femininos que são diferenciados e, muitas vezes, separados e hierarquizados, e que têm como efeito a maior valorização das condutas de um sobre o outro (idem, p. 12).

Na cena seguinte, quando o conselheiro imperial sai do rio, parece ter sua sexualidade posta em xeque. Não reproduz os comportamentos ditos masculinos, ao som de várias gargalhadas, sendo também motivo de sátira. Com uma toalha na cabeça e outra no tronco, reclama do sapato encharcado e diz não gritar como mulher, mas emite um grito "não masculinizado" logo em seguida, onde todas as suas ações inclinam-se a uma incorporação feminina e convergindo com os expostos acima.

Adiante, enquanto o Exército marcha para a batalha, canta-se a música "Alguém pra quem voltar":

Por um longo tempo estamos só marchando / Como um gado velho que vai se arrastando / O som do tambor varrendo os pés / Sentindo o chão faltar / Ué! Pensem em ter alguém pra quem voltar / O que? / Foi o que eu disse / Alguém pra quem voltar / Sua pele branca como a lua / Estelas no olhar / Mostrar a ela meu poder / Feridas pra cuidar / Eu não me importo com o que veste ou com beleza / Mas se cozinha com destreza / Boi, porco, frango, hum! / O sucesso com as garotas é enorme / E aumenta mais usando um uniforme / A saudade só aperta quando vamos guerrear / Queremos ter alguém pra quem voltar / Minha garota é demais / Com ela eu sou o tal / É, mas se ela o cérebro usar / Vai ser a maioral? / Não! / Eu sei que sou sensacional, irresistível / Sua modéstia é terrível / A mulher pra mim tem que ser um colosso / A mulher pra ele é a mãe que faz o almoço / Quando a guerra acaba e a vitória vem nos alegrar / Queremos ter alguém pra quem voltar / Desejo ter alguém pra quem voltar / Alguém pra quem vol...

A música enaltece o desejo íntimo dos soldados em voltar para casa e lá encontrar suas respectivas mulheres. Uma delas deve ter a pele branca, a outra deve, inclusive, saber cozinhar. Fica mais uma vez evidente o papel esperado para as mulheres, de submissão e serventia aos maridos (GOELLNER, 2003). Ainda, contempla-se apenas mulheres de pele branca, elidindo as demais, no que para nós soa minimamente como uma estratégia de (re)consolidação da representação de etnias através de desenhos animados, onde o padrão caucasiano acaba sendo privilegiado em detrimento dos demais.

Pensando sob este viés, identificamos aqui marcadores sociais das diferenças que são definidos em contextos sócio-histórico-culturais, consolidando valores, normas e 
expectativas sobre os sujeitos de forma hierarquizada. A partir desta configuração, existe um padrão universal, melhor valorizado, dignificado e endeusado, em constante alvo de busca por integrantes de uma sociedade. Tal modelo apresenta traços que versam sobre gênero, sexualidade, raça e classe social, privilegiando o homem cisgênero ${ }^{5}$, branco, heterossexual, cristão, de classe média e letrado (CASTRO, 2014). Para compreender tais diferenças, desigualdades e hierarquias, é crucial entender como tais marcadores sociais de diferença se articulam entre si, resultando em um processo que se denomina como interseccionalidade (PISCITELLI, 2008).

Este termo surge do debate internacional sobre categorias emergentes das diferenças sociais articuladas com gênero no final da década de 1990, tornando-se amplamente discutidas no Brasil a partir dos anos 2000 (PISCITELLI, 2008). Pode ser compreendido como as maneiras de interação entre formas subordinadas, ou seja, o somatório e/ou superposição de opressões. Por exemplo, uma mulher negra sofre a intersecção de dois marcadores, a opressão por ser mulher e por ser negra, denunciando, assim, o cruzamento de eixos sociais que definem, reconhecem e classificam sujeitos (idem). Partindo deste raciocínio, torna-se possível complexificar a heteronormatividade a outros marcadores sociais, tais como raça, etnia e classe social, através de significações e atribuição de valores, o que culmina na invisibilização e marginalização dos sujeitos dissidentes ao padrão e, portanto, desvalorizados.

Outra leitura que também podemos vislumbrar ainda se tratando sobre padrão de beleza, raça e etnia é sobre o espaço ao qual a narrativa é desenvolvida. A história se passa em algum período da Dinastia Han (206 a.C. - 220 d.C), onde a China desenvolveu consideravelmente sua agricultura, artesanato e o comércio de modo geral, estendendo sua influência política, cultural e territorial sobre a Coreia, Mongólia, Vietnã e Ásia central (SCARPARI, 2006). A questão racial, neste contexto, encontra-se intimamente inter-relacionada aos fatores sociais historicamente construídos.

Ao longo do período imperial chinês (séc. III a.C. - séc. XX d.C.) surgiram representações de uma beleza masculina calcada na representação de intelectuais brancos, ao mesmo ponto que camponeses apresentavam tez mais escuras em função da maior exposição ao sol. Essa primeira hierarquização privilegiava o intelecto ante ao trabalho braçal, atribuindo-lhe aspectos de raça conforme uma perspectiva dual de assimilação: 1 - intelectual $=$ branco $=$ mais valorizado versus 2 - camponês $=$ bronzeado $=$ menos valorizado (SAKAMOTO, 2016).

O conceito acima explicitado expõe como a questão racial encontra-se interligada aos padrões de beleza. Na China, temos um modelo que parece ser muito mais aceito que os demais, caracterizado como um rosto ovalado, pele branca, cabelos lisos e corpo delgado e delineado (idem) - os(as) personagens do filme encontram-se majoritariamente aí contemplados, principalmente os(as) protagonistas. A retratação prioritária de apenas estes atributos contribui para uma valorização primariamente desigual entre etnias, que a narrativa também sustenta através do cunho empregado à música em questão.

5 Termo que designa sujeitos homens que se reconhecem no próprio gênero que lhes foi atribuído no nascimento. 
Temos neste canto, portanto, a prescrição da seguinte denotação: os homens devem manifestar o desejo de lógica heteronormativa às mulheres brancas, valoradas hierarquicamente acima do que as demais etnias. Essa premissa contribui para embasar conceitos racistas, ainda que de forma sutil, pois legitima apenas um desejo a apenas um modelo de mulher, aquela que, além de branca, corresponde aos estereótipos clássicos de gênero. Desta forma, invisibiliza-se o desejo ao heterodissidente, aos(às) negros(as), aos menos favorecidos financeiramente, ou a todo(a) aquele(a) que não corresponde ao padrão universal.

Ainda analisando o discurso da última canção, podemos perceber que tais soldados se acham "bonitões e irresistíveis", sendo lucro à mulher que com ele estiver, pois se torna uma imposição de plenitude ter uma esposa. Qualquer vislumbre que destoe dos padrões estabelecidos para homens e mulheres, da conduta de cada um, do matrimônio, da defesa à Pátria, da honra à família, enfim, de tudo que foi estabelecido e é sustentado pela norma fílmica, não é visto com bons olhos na trama.

Após uma cena de luta e um ferimento, Mulan precisa ser avaliada pelo médico do Exército e é descoberta, sendo condenada pelo fato de ser uma mulher e ali estar de forma nebulosa. Em momento de crise novamente, ela fica na dúvida se suas atitudes foram para honrar o pai ou para se afirmar enquanto merecedora de honra, demonstrando a prevalência de um sistema hierarquizado que não reconhece esforços femininos e masculinos com os mesmos parâmetros (HEILBORN, 1993). Ainda nesta cena, denuncia-se que os corpos que não se conformam com os modelos a eles impostos são marginalizados, fracassados e indignos de mérito, reconhecimento e sobrevivência.

Mais tarde, quando a tropa chinesa chega à cidade imperial, é recebida com glórias, entretanto ninguém destaca que a suposta vitória havia sido fruto das ações de Mulan. O general não ouve as alertas da moça com relação à presença dos hunos sobreviventes, o que é curioso pelo fato que ela mesma levanta: ele acreditava em Ping, mas não acredita em Mulan. A mesma atitude é tomada pelos demais presentes e, segundo Mushu, isso ocorre porque ela voltou a ser mulher, ou seja, ser mulher naquela sociedade enfatiza as hierarquias de gênero que privilegiam o masculino ante ao feminino. A visão que daí emerge aponta que mulheres não entendem de guerra.

Nas cenas que se seguem, os hunos atacam a cidade e sequestram o Imperador. Mulan arquiteta um plano para salvá-lo e recruta alguns de seus colegas como Yao, Ling e Chien-Po que, assim como a protagonista outrora, agora transitam entre os gêneros e performam três mulheres através de vestimentas e discursos corporais. Em nenhum momento sofrem a repressão que Mulan sofreu em seu trânsito de gênero. Muito pelo contrário, são ovacionados porque junto dela resgatam o Imperador.

Após resgatarem o Imperador e explodirem o Palácio, o conselheiro surge ridicularizando Mulan pelo fato de ela ser mulher e não ser digna de nada, a não ser da culpa de ter causado tamanho transtorno na cidade imperial, mais uma vez reforçando a hierarquização de gênero: ela só não é digna porque é mulher, se fosse homem seria vangloriado.

O Imperador reconhece as vitórias de Mulan, bem como a multidão, no entanto cabe-nos elencar que toda a glória conferida à protagonista pelas demais pessoas só ocorre 
depois que o homem mais poderoso daquele contexto a reconheceu, caso contrário a garota ainda seria nada. Ele sugere ao capitão Shang que a despose, atribuindo a ela as "qualidades de mulher" mais esperadas e valorizadas: "A flor que desabrocha na adversidade é a mais bela de todas [...] Não se encontra uma garota como aquela em toda a dinastia da China", novamente a flor atrelada ao feminino e, devido às suas qualidades, Mulan seria uma boa esposa, o sonho de qualquer homem.

Quando a protagonista retorna, o pai reconhece a honra de apenas tê-la como filha, sem nenhuma provação a mais (lembrando que isso só acontece porque ela salvou a China). A avó reproduz o discurso comum quando reclama da neta não ter voltado com um marido, uma vez que naquele cenário é o que se esperaria de uma mulher. No final, o ancestral que anteriormente atribuiu a personalidade de Mulan ao lado da família de sua esposa agora a reconhece como membro de seu lado genealógico em função de suas conquistas, ou seja, só é digna porque conquistou alguma coisa, caso contrário continuaria sendo nada.

\section{CONSIDERAÇÕES FINAIS}

A trama apresenta aspectos relacionados aos gêneros que são intrigantes. Como pudemos perceber, o discurso prevalente é machista e hierarquizante, além de afirmar e consolidar o binarismo de gênero. As funções atribuídas aos homens são diferentes das mulheres conforme a construção e reprodução dos estereótipos: o homem deve ser forte, viril, sujo, agressivo e manter-se em constante vigilância para reproduzir tais padrões sobre a ameaça de ser enquadrado como feminino, além de claro, ter uma esposa que o honre. À mulher, cabem-lhe as tarefas domésticas, além de zelar pelo seu corpo e pelo marido, sendo que a única forma de perpetuar a honra da família é se casando e se tornando boa mãe. Qualquer manifestação que se apresente diferente destas é condenada. Percebemos, neste discurso, a prevalência de tratamentos diferenciados e desiguais, regidos por mecanismos de poder que privilegiam o masculino em detrimento do feminino (HEILBORN, 1993).

Desenvolvida em um espaço de estrutura social, a narrativa é produto de um esforço promovido pelas instituições sociais, uma vez que esta prepara a totalidade dos seres para se inserirem de diversos modos numa sociedade cada vez mais complexa conforme oportunidades, flexibilidade de raciocínio, adaptação às novas situações, persistência e capacidade de interação e cooperação. Logo, as vivências são refletidas nas estruturas sociais e vice-versa.

As personagens vivenciam momentos de crise por conta da não adequação ao sistema heterocompulsório e suas imposições/cobranças, revelando a instabilidade na manutenção deste sistema que apenas se sustenta hegemônico em função de sua reiteração exagerada, contínua e retroalimentada. Embora o final do filme exiba a máxima do "felizes para sempre", cabe ressaltar que Mulan só é reconhecida como digna por conta de seu sucesso em sua aventura, caso contrário, sua desonra seria avassaladora. As hierarquias de gênero sustentadas no binarismo homem x mulher, pelo que o filme explicita, ainda se consolidam. 
julho/2018

A obra traz deslocamentos curiosos sobre identidades, papéis e desempenhos sociais, no entanto, limita-se a premissas dadas, naturalizadas e que promovem performances em universos reclusos, limitantes e demarcadas por relações binárias e contrapostas. Neste contexto, reassisti-la favorece a discussão e ampliação de questões inquietantes sobre cenários pedagógicos e culturais ainda marcados e classificados por diferenças sociais. É importante estar atento à forma que a indústria cinematográfica propõe às crianças, uma vez que corrobora consubstancialmente com os papéis e desigualdades de ordem interseccional.

\section{REFERÊNCIAS}

BALISCEI, João Paulo; CALSA, Geiva Carolina; STEIN, Vinícius. "(In)felizes para sempre"?: Imagens da Disney e a manutenção da heteronormatividade. Bagoas - Estudos gays: gêneros e sexualidades, v. 10, n. 14, p. 163-180, 2016.

BUTLER, Judith. Bodies that matter: on the discursive limits of 'sex', Londres, Routledge, 1993.

. Problemas de gênero: feminismo e subversão da identidade. Rio de Janeiro, editora Civilização Brasileira. Col. Sujeito \& História, 8.ed. 2015. 288 p.

CASTRO, Taís Borges de. Heteronormatividade e outros marcadores sociais no jornalismo: uma análise das revistas Claudia e TPM. Trabalho de conclusão de curso (Monografia), Universidade Federal do Rio Grande do Sul, Porto Alegre, 2014. 103 p.

GOELLNER, Silvana Vilodre. Bela, maternal e feminina: imagens da mulher na Revista de Educação Physica. ljuí: Unijuí, 2003.

. Feminismos, mulheres e esportes: questões epistemológicas sobre o fazer historiográfico. Movimento. Porto Alegre, v. 13, n. 2, p. 171-196, mai./ago., 2007.

HEILBORN, Maria Luiza. Gênero e hierarquia: a costela de Adão revisitada. Estudos Feministas, Vol. 1, No. 1, 1993. p. 50-82.

IGLESIAS, Matías López; ZAMORA, Marta de Miguel. La fémina Disney: análisis y evolución del personaje feminino en cuatro películas de la factoría Disney. Revista Sociedad y Economía, Cali, n. 24, p. 121-142, ene./jun. 2013.

LOURO, Guacira Lopes. Pedagogias da sexualidade. In: LOURO, G. L. (orgs). O corpo educado: pedagogias da sexualidade. 3a. ed. Belo Horizonte: Autêntica, 2010. p. 7-35.

NEGREIROS, Teresa Creusa de Góes Monteiro; FÉRES-CARNEIRO, Terezinha. Masculino e feminino na família contemporânea. Estud. pesqui. psicol., Rio de Janeiro, v. 4, n. 1, jun. 2004.

PARAÍSO, Marlucy Alves. Raciocínios generificados no currículo escolar e possibilidades de aprender. In: LEITE C.; PACHECO J. A.; MOREIRA A. F.; MOURAZ A. (Org.). Políticas, fundamentos e práticas do currículo. Porto: Porto Editora, 2011, v. 1, p. 147-160.

PISCITELLI, Adriana. Interseccionalidades, categorias de articulação e experiências de migrantes brasileiras. Sociedade e Cultura, v.11, n.2, jul/dez., p. 264-274, 2008.

REIS, Cristina d'Ávila; PARAÍSO, Marlucy Alves. A constituição de corpos guerreiros no currículo escolar. Educação \& Realidade, v. 38, n. 4, p. 1243-1266, out./dez. 2013. 
SABAT, Ruth Ramos. Infância e gênero: o que se aprende nos filmes infantis? Universidade Federal do Rio Grande do Sul. 2001. Disponível em: < http://www.ced.ufsc. br/ nee0a6/truthsa.pdf>. Acesso em 27. Out. 2017.

SANTOS, Caynnã de Camargo. O vilão desviante: Ideologia e Heteronormatividade em filmes de animação longa-metragem dos estúdios Disney. Dissertação (Mestrado) - Pósgraduação em Estudos Culturais, Universidade de São Paulo, São Paulo, 2015. 143 p.

SAKAMOTO, Camila. Racismo na China e Padrão de Beleza. Blog China Link Trading, 2016. Disponível em: < http://www.chinalinktrading.com/blog/racismo-na-china-epadrao-de-beleza/> . Acesso em: 05. Nov. 2017.

SCARPARI, Maurizio. Grandes civilizações do passado: China antiga. Trad. Alexandre Martins. Barcelona. Ediciones Folio, 2006. 287 p.

SCHECHNER, Richard. "O que é performance?". In: Performance studies: an introduccion. 2. ed. New York \& London: Routledge, trad. R. L. Almeida, classe 3, abril 2011, p. 28-51.

SILVA, Tomaz Tadeu. O currículo como fetiche: a poética e a política do texto curricular. Belo Horizonte: Autêntica, 1999.

XAVIER FILHA, Constantina. Gênero e resistências em filmes de animação. Pro-Posições, [S.I.], v. 27, n. 1, p. 19-36, jun. 2016.

\section{FILMOGRAFIA}

MULAN. Direção: Tony Bancroft e Barry Cook. Filme de animação. Estados Unidos Orlando/ Flórida. Produção: Walt Disney Pictures, Blu-ray Disc, 2013. 88 minutos, som, cor, dublado, livre. 